\title{
Smart LPG Monitoring and Automatic Booking System using IOT
}

\author{
Jayesh Gupta ${ }^{1}$, Abhijit Patil ${ }^{2}$, Samadhan Rajgire ${ }^{3}$, Tejashree Kadus ${ }^{4}$ \\ ${ }^{1,2,3,4}$ BTech Student, Department of Mechanical Engineering, \\ MIT Academy of Engineering, Pune.
}

\begin{abstract}
In recent years there has been a rapid development in technology which has made human life easier in several aspects. LPG is a need of every and is widely used for cooking. Some of the common problems experienced during its usage are, the gas cylinders go empty while the peak cooking hours, incognizance of the current status of gasoline present in the container, and the failure to prophesy the working days of the LPG cylinder once installed. All these lead to inconvenience in its use. To deal with these issues Smart Gas Kit is an ideology put forward. It mainly focuses on the application of the IoT used for measuring and displaying the gasoline content present in household LPG cylinder and automatic booking of a new LPG cylinder. The additional advantage of the system also involves predicting the working days of the gasoline content. The continuous weight measurement of gas on regular basis is done using a load cell which is interfaced with a Microcontroller. The current status and the booking notifications are notified to the user on their mobile phones via Bluetooth module. The entire framework work towards making the LPG chamber booking system more automatized without any human intercession.
\end{abstract}

Keywords: LPG gas, Loadcell, Arduino, Bluetooth-module, Atomization.

\section{I.INTRODUCTION:}

Today in present era where technological advances are at its zenith, there's not even a single sector which remains untouched by technology. Technology has not only made our lives simpler, but also offers a high level of safety and security wherever required. One of the most significant technologies is IoT (Internet of Things) which makes the way to connect two hardware devices through internet. It is widely used in various sectors like medicine, industries etc, and its Implementation is also expanded in domestic sectors. In our day to day lives, we all use LPG fuel for cooking our daily meals. On account of its flexibility it is used in numerous sectors. Today, booking an LPG cylinder is simply a text message away. Petroleum companies have introduced the customer-friendly service called as Interactive voice Response technique for their customers. Most of the times in our daily use, users find it difficult to figure out the quantity of LPG left in the cylinder leading to situations where the gas goes empty. This cause inconvenience in its use. In such a state of affairs, associate degree efficient technique to watch the amount of LPG within the cylinder is needed, so the users are tuned in to the LPG level at intervals within the cylinder. Thus, there is a huge demand for an IoT system which is automated in measuring the level of gas and notifying it to the user in order to book the cylinder pre before it gets empty.

The Framework of paper proposes a microcontrollerbased system that monitor the gas quantity in the container.
The weight of cylinder is measured using load cell sensor which intern works on the principle of piezoelectric sensor.it continuously measures the weight and the send the electric pulse to the microcontroller i.e. Arduino. When system detects the weight of cylinder below particular level, it alerts the user for cylinder booking, and place a refill order in the respective branch. It also provides additional features such as notifying the current status of gasoline present in the container and predicting the working days of the gasoline content. the proposed system uses a Bluetooth Module for the connection of an android device with the system. The main application of this proposed system is to overcome the shortcomings such as delay and pre-booking of the LPG cylinder by the consumers.

\section{LITERATURE SURVEY:}

Different techniques were introduced for measuring the amount of gasoline present in the cylinder and scheduling its booking The system in which, the inbuilt pressure sensor in RFID was used to measure the level of the gas inside the cylinder. The output of the pressure sensor was given to the PIC controller, where the voltage corresponding to the gas weight was stored. The same was displayed on the LCD, which was connected to the output port of the controller. A threshold value was set in the controller. Once the threshold level was reached, the voltage value was given to the alarm, which alarmed the user [1].

The study in which the frequencies of tone generated by knocking on the outside surface of the container was used to detect the liquid level inside. A detailed model was based on Euler-Bernoulli beam theory to study the feasibility of the method for a cylinder with complicated but practical structure and the results show that experimental data agree well with the theoretical analysis. The results indicate that the proposed model can accurately explain the behaviour of the vibratory frequencies under different liquid levels. The apparatus can be successfully implemented to automatically sense the near empty condition of the gas cylinder [2].

Gas flow measurement devices were used to measure the pressure in the cylinder different equipment's such as Pitot tubes work by comparing the pressure in a small diameter tube (impact pressure) to the static pressure around the tube. In Venturi Pressure measurements are taken before and at the mid-point of a constriction, then the flow rate is calculated from the difference in these two measurements. Orifice plates are a well-proven flow measurement technology. Because orifice plates are interchangeable, a technician can change the plate size to achieve desired pressure differential with changing flow rates [3]. 
Kumar Keshamoni and Sabbani Hemanth planned the sensible Gas Level observance, Booking and Gas outpouring Detector victimization IoT. During this the gas amount within the instrumentation is ceaselessly monitored and it additionally intimates the various branch so as to position the new LPG cylinder. The Radio frequency module is used in order to make the user to use it easily and this module consists of the transmitter and receiver kit. The transmitter is an encoder kit which is fixed in the main board and the receiver is a decoder kit which is fixed in the sub board. In addition to easy usage, it also has the advantage that it gives the same information. The temperature sensor is also used in order to detect the errors which occurs due to the surrounding environment. The main drawback in this system is that the use of processor instead of the controller and moreover there is no security for the user [4].

\section{PROPOSED SYSTEM:}

In order to address the issue, the proposed system is employed. it overcomes the complications of existing system and focuses on providing functionalities like detecting gas level and informing user the status of gasoline content. The system framework consists of weight measuring Load sensor interfaced with Arduino Nano and the Bluetooth module for connectivity. This embedded processor is used for real time monitoring of the data parameters. the weight measuring load sensor is attached to a mechanically designed movable trolley which holds the cylinder in it. The load sensor attached to the bottom of this plate measures the weight of the cylinder periodically and send the data to hx711 amplifier. The amplifier converts the analog signal to the digital signals and send it to the microcontroller Arduino Nano. The whole working on the framework is accomplished by executing a code inbuild in the microcontroller, it analyses the input readings of load sensor and send the obtained output results of the current status of gasoline content, working days of the gas, and the alertness of gas booking once the gas is below its set threshold value the desired results are notified to the user on their mobile phone via a Bluetooth module. The entire module work towards making the LPG cylinder booking system more automatized without any human intercession.

\section{BLOCK DIAGRAM OF PROPOSED} SYSTEM:

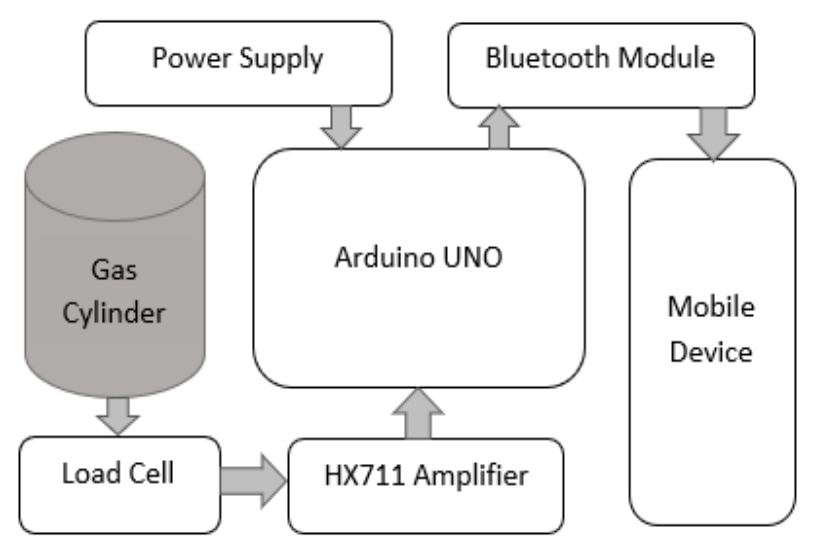

\section{METHODOLOGY (FLOW CHART)}

- User Interface Flow-Chart:

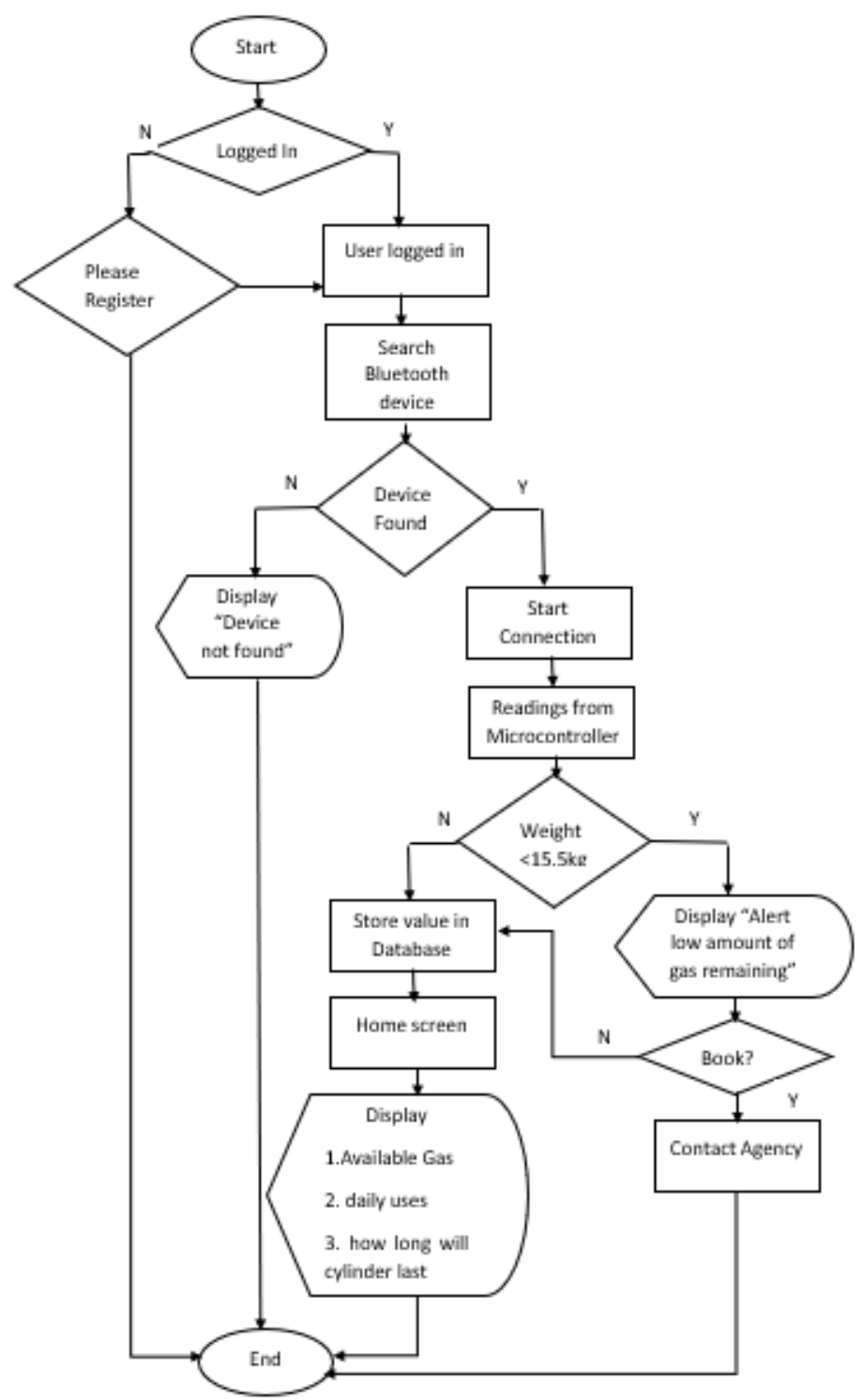

VI. SYSTEM ARCHITECTURE:

\begin{tabular}{|l|l|}
\hline $\begin{array}{l}\text { Sr. } \\
\text { no }\end{array}$ & Components \\
\hline 1. & Arduino Nano \\
\hline 2. & Load cell \\
\hline 3. & HX711 Amplifier \\
\hline 4. & Bluetooth Module \\
\hline 5. & Mechanical Designed trolley \\
\hline
\end{tabular}

a. Arduino Nano:

The Arduino Nano is a small, complete, and breadboardfriendly board based on the ATmega328P (Arduino Nano 3. $\mathrm{x}$ ). It has more or less the same functionality of the Arduino Duemilanove, but in a different package. It lacks only a DC power jack, and works with a Mini-B USB cable instead of a standard one. This board is mainly used for developing embedded application involving high speed wireless communication, real time data monitoring and control, interactive control panels. Arduino Nano in the system executes a code inbuild in it, it analyses the input readings of load sensor and send the obtained output results of the 
current status of gasoline content, working days of the gas, and the alertness of gas booking once the gas is below its set threshold value to the Bluetooth module.

- 8 analog inputs ports: A0 A7

- 14 Digital input / output ports

- 6 PWM ports

- $\quad$ Support for external 5V 12V DC power supply

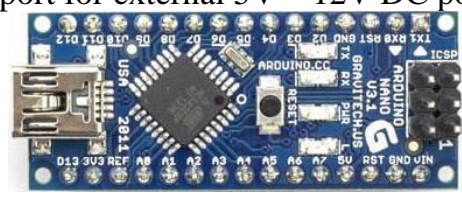

Fig1: Arduino Nano

b. Load Cell:

Load cell acts as a transducer; it creates an electrical signal whose magnitude is directly proportional to the force that is being measured. The load which is measured is then transduced into a signal. The output of transducer can be scaled to calculate the force applied to the load cell. We are using Load cell sensor for measuring weight of cylinder. Load cell sensor continuously measure weight of cylinder and send signals to amplifier.

- Insulation Resistance: >2000 OhmMax

- Excitation Voltage: DC 10V

- Material: Aluminium Alloy

- Weight: $22 \mathrm{~g}$

- Capacity: $30 \mathrm{~kg}$

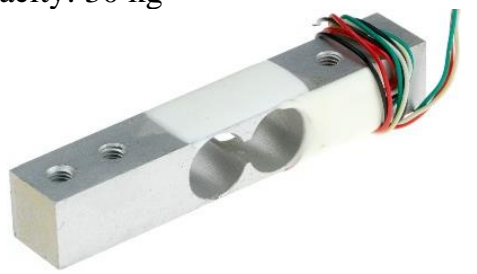

Fig2: Load cell

c. HX711 Amplifier:

This Load Cell Amplifier is a small breakout board for the HX711 IC that allows you to easily read load cells to measure weight. HX711 amplifier is used for converting the Analog signals received from load cell to digital signals for functioning of microcontroller.

- Operation supply voltage range: $4.8 \sim 5.5 \mathrm{~V}$

- Operation supply Current: $1.6 \mathrm{~mA}$

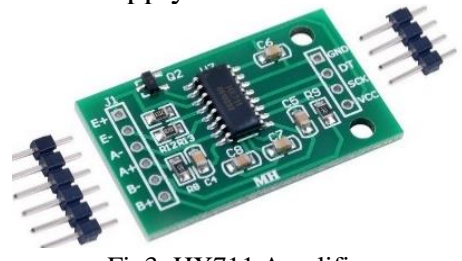

Fig3: HX711 Amplifier

d. Bluetooth module:

Bluetooth Module connects android device to Arduino board. HC-05 Bluetooth Module has 6pins. RX of Bluetooth module is connected to Tx of Arduino board and Tx of Bluetooth module is connected to $\mathrm{Rx}$ of Arduino board. Supply Voltage of Bluetooth module is $3.3 \mathrm{~V}$ to $5 \mathrm{~V}$ which is connected to $5 \mathrm{v}$ pin of Arduino.

- Frequency: $2.4 \mathrm{GHz}$

- Sensitivity: $\leq-84 \mathrm{dBm}$
- $\quad$ Power supply: +3.3VDC50mA

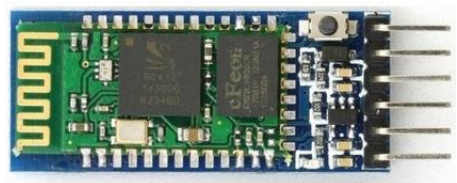

Fig4: Bluetooth Module

e. Mechanically Designed Trolley:

- Material: Aluminium

- Dimension: ID: $350 \mathrm{~mm}$

OD: $380 \mathrm{~mm}$

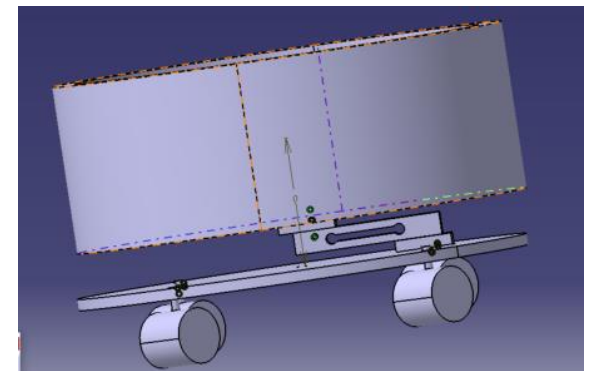

Fig5: Mechanical Trolley

VII. MOBILE INTERFACE:

Smart Gas Kit Mobile Application: A mobile application is developed which acts as a bridge between the user and the microcontroller. The desired outputs and results are displayed and notified to the user through this mobile application. the user have to register to this application in order to connect the Bluetooth module. The outputs received from the Bluetooth module are stored in the form of .xml file within the android mobile and can be extracted whenever necessary by retrieving it through file-handling. The daily consumption of Gasoline content is displayed in the graphical form depicting user friendly interface. Once the user receives the Alertness regarding the booking of cylinder a pop-up message asking for booking directs him/her to the number Dialpad.

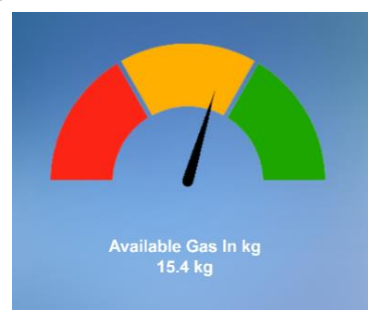

Fig6: Mobile App Interface

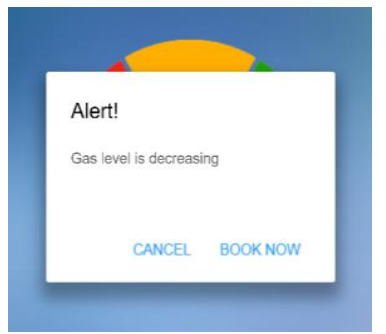

Fig7: Mobile App Interface 
VIII. FORMULATION AND RESULT:

\begin{tabular}{|c|c|c|}
\hline $\begin{array}{c}\text { Sr } \\
\text { no }\end{array}$ & Parameter & Formula \\
\hline 1. & LPG all day used & $\begin{array}{c}\text { Initial value of day - final } \\
\text { value used }\end{array}$ \\
\hline 2. & $\begin{array}{c}\text { How long the gas } \\
\text { will last }\end{array}$ & $\begin{array}{c}\text { (Available gas -14.5)/ Avg. } \\
\text { value of daily usage of } \\
\text { LPG }\end{array}$ \\
\hline
\end{tabular}

\begin{tabular}{|c|c|c|}
\hline $\begin{array}{c}\text { Sr } \\
\text { no }\end{array}$ & $\begin{array}{c}\text { Weight of } \\
\text { Cylinder }\end{array}$ & Result \\
\hline 1. & Below $15.5 \mathrm{~kg}$ & $\begin{array}{c}\text { Display Alert message on } \\
\text { Mobile Application }\end{array}$ \\
\hline 2. & Above $15.5 \mathrm{~kg}$ & $\begin{array}{c}\text { Display and store current } \\
\text { status value in Database }\end{array}$ \\
\hline
\end{tabular}

\section{FUTURE SCOPE:}

1) Voice feedback system can be included in detection system. this will notify the user through pre-recorded voice messages about the weight of cylinder.

2) The app can be linked with the online database and instead of Bluetooth module, wi-fi module can be used to transfer the daily recorded readings to the online database, this will help identifying the daily uses trends.

\section{CONCLUSION:}

The system proposed investigated different parameters dealing with the technologies used for gas level detection. It started with briefing the issues faced when the LPG cylinder goes empty while cooking and the inconvenience caused due to it. Survey carried out depicted the different technologies with the same ideology but were costly. Important factors were designing a simple and feasible system to deal with the issue. Thus, with the application of IOT a cost-effective gas level detection system was proposed, and successfully implemented along with pre-booking alertness it also gives an approach towards knowing the current amount of gas left in the cylinder and predict the working days. The use of this system avoids the delay booking of cylinder and eliminates all the inconvenience caused due to it. Hence the entire framework worked towards automizing the LPG chamber booking system.

\section{X1. REFERENCES:}

[1] Mr. Akshay D. Prabhu, Mr. Ashwin D. Pathak, "Gas Leak Detector using Arduino UNO Microcontroller", International Journal for Research in Applied Science \& Engineering Technology (IJRASET), Volume 5, July 2017

[2] Al-Karaki, J. N. and A. E. Kamal (2004). "Routing techniques in wireless sensor networks: a survey." Wireless communications, IEEE 11(6): 6-28.

[3] S. Rajitha, T. Swapna, "Security alert system using GSM for gas leakage" International Journal of VLSI and Embedded SystemsIJVES

[4] Ravindra R. Hiwase, Priya K. Kewate, Sushmita P. Tajane, JitendraWaghmare "Automatic LPG Cylinder Booking and Leakage Detection using Arduino UNO” IJESC.

[5] Shital Imade, Priyanka Rajmane, AishwaryaGavali, V.N. Nayak wadi "Gas leakage detection and smart alerting system using iot" International Journal of Innovative Research \& Studies.

[6] L. K. S. Rohan Chandra Pandey, Manish Verma, "Internet of things (IOT) based gas leakage monitoring and alerting system with MQ-2 sensor," International Journal of Engineering Development and Research, Vol. 5, 2017.

[7] Shailendra Kumar Dewangan3 Praveen Singh Rathore4 Abid Khan1, Neju K. Prince2. Gsm based automatic lpg ordering system with leakage alert. IJRET: International Journal of Research in Engineering and Technology, 3(12), Jun-2014.

[8] P. M. Vidya, S. Abinaya, G. G. Rajeswari, and N. Guna, "Automatic lpg leakage detection and hazard prevention for home security," in Proceeding of 5th National Conference on VLSI, Embedded and Communication \& Networks on April, vol. 7, 2014. 